\title{
Optimization of processes in railways based on the cost management model
}

\author{
Valery Vorobyov ${ }^{1, *}$, Aleksey Manakov ${ }^{1}$, Anatoly Reger $^{2}$, and Iuliia Tanaino ${ }^{1}$ \\ ${ }^{1}$ Siberian Transport University, 630049 Novosibirsk, Russia \\ ${ }^{2}$ West-Siberian Railway - branch of Russian Railways JSC, 630004 Novosibirsk, Russia
}

\begin{abstract}
The main aim of activities of the branches of vertically integrated Russian Railways JSC is enhancing of manageability and efficiency of business operations. At the current stage, the issue of optimization of costs for product transportation and facilities maintenance in the system of production and technological processes of the railway network has gained relevance. The purpose of this study is development of a mathematical model for the logistic system of transportation, storage, cargo-handling operations, facilities maintenance and reconstruction. Methods of spatial and dynamic modeling in the structure of end-to-end planning of operations were used in the study. Optimization criterion is aggregate cost minimization. Cost function is proposed in the form of local functions of multiple sections along the railway network. The modeling result consists in determining the plans of transportation and supply with minimum costs.
\end{abstract}

\section{Introduction}

Public railway transport keeps the leading position in Russian transportation system. It has no alternative in handling massive and stable freight traffic delivered on middle and long distances [1]. Railway transportation is meant to provide delivery of raw materials and primary products.

The system of freight transportations are subject to delays which impact the investment decisions. In turn, costs depend on correct and timely input data [2, 3, 4, 5].

Considerable growth in the number of freight trains in sections of Trans-Siberian Railway (in the direction Kuzbass - Far East) is provided until 2020 (Table 1).

\footnotetext{
*Corresponding author: decansgd@stu.ru
} 
Table 1. Target indicators of freight transportations until 2020.

\begin{tabular}{|l|c|c|c|}
\hline \multirow{2}{*}{ Zone } & \multicolumn{3}{|c|}{ Number of freight trains per year, piece } \\
\cline { 2 - 4 } & 2018 & 2019 & 2020 \\
\hline Inskaya - Mariinks & 6 & 6 & 12 \\
\hline Mariinks - Taishet & 6 & 6 & 12 \\
\hline Mezhdurechensk - Taishet & 1 & 3 & 8 \\
\hline Taishet - Karymskaya & 7 & 9 & 20 \\
\hline Karymskaya - Khabarovsk & 7 & 9 & 20 \\
\hline Khabarovsk - Smolyaninovo & 7 & 9 & 20 \\
\hline
\end{tabular}

Increase of the number of trains with the weight of 7,100 tones from the initial point of freight traffic (Kuzbass) till the destination point (seaports of Primorsky region) is possible in case of implementing investment projects of Eastern railway polygon development until 2020. Implementation of such projects, as well as maintenance of Russian railway network requires considerable economic costs related to supporting reliability of infrastructure facilities and providing safety of transportation process [6-7].

According to conservative scenario of the Transport Strategy of the Russian Federation until 2030, the estimate amount of financial resources is 72 trillion 465 billion rubles, including federal budget funds in the amount of 20 trillion, 40 billion rubles are funds of legal entities in the framework of public-private partnership. Business operations play a significant role in organization of production activities and managerial structures operation, which became the reason for major reorganization in railway transport [8-9]. The issue of business interest agreement between transportation process organizers and infrastructure facilities owners, as well as alignment of indicators of quality and amount of work keep their relevance.

A number of unsolved systemic problems still exists in the transportation system in general and in its certain divisions, which is conditioned by the increasing demand for transportation services ever growing in the predicted perspective. The required integration in managing development and operation of transportation system is not provided; dynamics of the environment expressed in functioning of modern enterprises in high complexity and uncertainty conditions is not accounted; new low-cost methods for interaction between the manufacturer, operating company, transportation service provider, and customer are insufficiently developed; a new paradigm of scientific knowledge is not formed to provide the gound for common understanding of new notions, categories, methods and principles of organizational and managerial changes in a railway network in time and space [10-11].

Among the above issues, a relevant scientific problem is cost optimization in production, technological and organizational processes in railways operation based on modeling and forecasting of goods supply via local transport network. Methods and model of solutions for similar tasks exist $[5,12]$. However, they do not consider differentiation of planning horizons in the railway polygon represented by local transport network, including take-off points, classification yards, destination points and the connecting sections (hereinafter mentioned as "sections") with rolling mode of end-to-end planning, which provides regular development of plans with a shift on a certain time unit. Maximum efficiency of problem solving shall be reached by permanent final goal orientation when performing all types of managerial actions, such as: developing product supply plan that 
provides minimization of aggregate cost of freight transportation on track sections; organization of product supply on sections; product storage while loading, transporting and unloading; maintenance, repair, reconstruction, retrofit and development of transport infrastructure (railway tracks, stations, cargo-handling equipment, etc.). The existing research in the field of cost management in industrial processes of transportation with the use of spatial and dynamic modeling methods are insufficient.

The purpose of this study is development of a model for transport and logistic system of transportation, storage, cargo-handling operations, facilities maintenance and reconstruction.

Scientific novelty of the study is provided by integral use of spatial and dynamic methods of representation of transport systems for defining the optimum number of supply batches while planning transportations with lowest possible costs.

\section{Research methods}

The problem of cost optimization in production, technological and organizational processes is conditioned by the paradigm of labor productivity increase as the main category of economic development and growth in prosperity under the influence of human factor. Object of the study is a railway polygon, subject is costs of technological and organizational processes. The research hypothesis is as follows: cost minimization on the railway polygon is possible and can be reached when developing a transportation plan by mathematical modeling of technological and organizational processes.

The study has the following tasks:

1. define informational parameters of transportations in the railway polygon;

2.define the main assumptions related to freight transportation costs in the polygon of railway network;

3. review mathematical models and methods for determining the extent of their applicability to transport systems presentation.

4.develop a mathematical model of a transport and logistic system including cost functions in the transportation polygon of the railway network;

5. formulate a task for defining freight transportations plan with minimum cost functions and satisfactory balance: accumulation of cargo and traffic in original points, transit and terminal points with the account of existence of sections in railway network with and without preset amount of time consumed;

6. determine the economic order quantity with the account of the above hypotheses.

In theory and practice, the following assumptions related to freight transportation costs in the polygon of railway network are accepted:

1. Costs for freight transportation are directly proportional to tonne-kilometer performance.

2. Costs for organization of supply are directly proportional to the number of batches (sets, cars, etc.) on the studied section.

3. Costs for storage of one product batch at the point during cargo-handling operations or when transporting is directly proportional to the product of storage time multiplied by volume.

4. Costs for infrastructure maintenance and development on the section of the area are directly proportional to the number of product batches (freight traffic density) per unit of time.

5. Costs for developing cargo-handling equipment of a certain point of delivery/receipt are directly proportional to the amount of cargo delivered/received per unit of time.

The existing simulation models of production processes, as well as methods of linear and dynamic programming of transportation processes have been studied [12]. It is known 
that statistical models reflect the state of technological process at a given moment of time, stationary models account time intervals between the initial moment of input disturbance and the current moment of time under external actions, nonstationary models allow simulating production process the parameters of which depend on the current time and the initial time of input disturbances action [13]. In continuous models, production parameters are defined for any moment of time, in discrete models the production parameters are defined in discrete moments of time. Spatial models represent technological process in space (continuous linear objects, spatial objects), whereas lumped parameter models disregard spatial coordinates of an object. Deterministic models are clearly defined by input parameters, constraints and the target function, stochastic (probabilistic) models account impact of random factors on the technological process.

The approach to developing a cost management model for production processes in the railway network based on spatial and dynamic models that represent space and time of their occurrence, is considered the most efficient.

The railway polygon is characterized by the following informational parameters: the total operation time of the network is unlimited; the intensity of cargo-handling operations at each point of the network is permanent; the transport network includes only points of loading, handling and unloading (transit points are excluded); the costs for product storage in the facilities of any network point during the setup time, and the costs for developing facilities and equipment for storage and setup operations are considered negligible and will not be accounted further on.

\section{Results}

The purpose of the study is implemented in the following model, for its description the following nomenclature is used:

Let us assume that Y1, Y2, Y3 are a multitude of loading points, classification yards, and destination stations respectively.

$$
Y_{1} \cup Y_{2} \cup Y_{3}=Y ; \quad Y_{1} \cap Y_{2}=\varnothing ;
$$

$q_{i}$-volume of loaded product at the $i$-th point $\left(I \in Y_{l}\right)$;

$B_{j}$ - volume of unloaded product at the $j$-th point $\left(j \epsilon Y_{2}\right)$;

$S_{j}$ - multitude of sections in the railway network, $<i j>$, adjacent to the point $j(j \in Y)$;

$q_{i j}$ - freight traffic on $<i j>\operatorname{section}\left(<i j>\epsilon S_{j}, j \in Y\right)$; $j \in Y)$;

$n_{i j}$ - number of load batches (sets, cars, etc.), on $<i j>$ section of the network $\left(<i j>\epsilon S_{j}\right.$,

$f_{i j}\left(q_{i j}, n_{i j}\right)$ - costs function $<i j>$ of the section $\left(<i j>\epsilon S_{j}, j \in Y\right)$;

$\mathrm{C}_{\mathrm{ij}}$ - transportation costs per unit of product on $\langle i j\rangle$ section;

$Z^{\mathrm{p}}{ }_{\mathrm{i}}$ - costs for developing cargo-handling facilities and equipment at the $i$-th point of $<i j>$ section per unit of loading/unloading intensity. By loading/unloading intensity we shall mean the amount of load handled at the $i$-th point per unit of time;

$\mathrm{Z}_{\mathrm{ij}}^{\mathrm{c}}$ - costs for maintenance and development of infrastructure of section $<i j>$ per unit of freight traffic intensity which denotes the number of load batches (sets, cars, etc.) transported on this section per unit of time;

$Z^{\mathrm{I}}{ }_{\mathrm{ij}}$ - costs for organization of transportation on $<i j>$ section per one load batch;

$\mathrm{Z}^{\mathrm{x}}{ }_{\mathrm{i}}, \mathrm{Z}^{\mathrm{x}}{ }_{\mathrm{j}}, \mathrm{Z}^{\mathrm{x}}{ }_{\mathrm{ij}}$ - product storage costs per unit of time at the initial $(i)$ and terminal $(j)$ points and on the section $\langle i j\rangle$ during cargo-handling operations and transportation respectively;

$\mathrm{t}_{\mathrm{ij}}, \mathrm{t}_{\mathrm{ij}}^{\prime}, \mathrm{t}_{\mathrm{ij}}$ - total time of load transportation on $\langle i j>$ section, loading at the $i$-th point and unloading at the $j$-th point respectively. 
Let us put down the cost function for the transportation polygon of the network as follows:

$$
F(Q, N)=\sum_{j \in Y} \sum_{C_{i j} \in S_{j}}\left[C_{i j} \cdot q_{i j}+Z_{i j}^{I} \cdot n_{i j}+\frac{Z_{i j}^{c}}{t_{i j}} n_{i j}+\left(\frac{Z_{i}^{p}}{t_{i j}^{\prime}}+\frac{Z_{j}^{p}}{t_{i j}^{\prime \prime}}\right) \cdot q_{i j}+\frac{1}{2}\left(Z_{i}^{x} t_{i j}^{\prime}+Z_{j}^{x} t_{i j}^{\prime \prime}+2 Z_{i j}^{x} t_{i j}\right) \cdot \frac{q_{i j}}{n_{i j}}\right]
$$

The function $F(Q, N)$ can be presented in the form of sum of local functions of costs on certain sections $f_{i j}\left(q_{i j}, n_{i j}\right)$ due to its separability for multiple sections of the transport network.

$$
F(Q, N)=\sum_{j \in Y} \sum_{C_{i j} \in S_{j}} f\left(q_{i j} n_{i j}\right)
$$

The task of determining the plans for transportation and supply can be formulated as follows: determine transportation plan $Q=\left\|q_{i j}\right\|$ and supply plan $N=\left\|n_{i j}\right\|$ that provide minimum of the function satisfying the conditions below:

- freight traffic at loading points:

$$
\sum_{<i j>\in S_{j}} q_{i j}+q_{j}=\sum_{<j i>\in S_{j}} q_{j i}, j \in Y_{1} \text {; }
$$

- freight traffic at transit points (classification yards):

$$
\sum_{<i j>\in S_{j}} q_{i j}=\sum_{<j i>\in S_{j}} q_{j i}, j \in Y_{2}
$$

- freight traffic at destination points:

$$
\sum_{<i j>\in S_{j}} q_{i j}=\sum_{<j i>\in S_{j}} q_{j i}+B_{j}, j \in Y_{3}
$$

- nonnegativity of transportations:

$q_{i j} \geq 0, i, j \in Y$;

- integrality and nonnegativity of the number of load batches:

$n_{i j}$ - integer; $n_{i j} \geq 0 ; i, j \in Y$.

- The task is approached based on the following assumptions:

- The railway polygon contain sections with preset amount of time consumed $t_{i j} t_{i j}^{\prime} t_{i j}^{\prime \prime}$;

- The railway polygon contains sections for which the specified values are linear functions of total amount of loaded and unloaded products:

$$
t_{i j}^{\prime}=\varphi_{i j}^{\prime} \cdot q_{i j}, t_{i j}^{\prime \prime}=\varphi_{i j}^{\prime \prime} \cdot q_{i j}, t_{i j}=\varphi_{i j} \cdot q_{i j} \text {. }
$$

Here, $\varphi_{i j}^{\prime}, \varphi_{i j}^{\prime \prime}, \varphi_{i j}$ are coefficients that characterize speed of loading, transportation and unloading.

1. The network also contains sections $<i, j>$ with preset time parameters $t_{i j}, t_{i j}^{\prime} t_{i j}^{\prime \prime}$.

A local cost function for a random section can be put as follows (for the convenience purpose we omit indices of section $\langle i, j\rangle$ ):

$$
f(q, n)=\alpha \cdot q+\gamma \cdot n+\left(\frac{z^{c}}{t_{1}}+\frac{z^{p}}{t_{2}}\right) \cdot q+\frac{z^{n}}{t_{3}} \cdot n+\frac{1}{2}\left(Z_{1}^{x} t_{1}+Z_{2}^{x} t_{2}+2 Z_{3}^{x} t_{3}\right) \cdot \frac{q}{n}
$$

Here, the parameters with index 1 and 2 characterize initial and terminal points respectively, whereas parameters with index 3 denote the section itself. 
In case the conditions of hypothesis 1 are satisfied with $q>0$ for some section, then the optimum number of batches on such section can be defined by the formula

$$
n=\sqrt{\frac{\left(Z_{1}^{x} t_{1}+Z_{2}^{x} t_{2}+2 Z_{3}^{x} t_{3}\right) \cdot t_{3} q}{2\left(z^{n}+\gamma t_{3}\right)}},
$$

And the local cost function is brought to the following:

$$
f=\alpha \cdot q+\left(\frac{z^{c}}{t_{1}}+\frac{z^{p}}{t_{2}}\right) \cdot q+\sqrt{Z_{1}^{x} \frac{t_{1}}{t_{3}}+Z_{2}^{x} \frac{t_{2}}{t_{3}}+2 Z_{3}^{x}} \cdot \sqrt{\left(z^{n}+\gamma t_{3}\right) q}
$$

In case the conditions of hypothesis 2 are satisfied with $q>0$ for some section, then the optimum number of batches on such section can be defined by the formula

$$
n=q \sqrt{\frac{\left(Z_{1}^{x} \varphi_{1}+Z_{2}^{x} \varphi_{2}+2 Z_{3}^{x} \varphi_{3}\right) \cdot \varphi_{3}}{2\left(\frac{z^{n}}{q}+\gamma \varphi_{3}\right)}},
$$

And the local cost function is brought to the following:

$$
f(q)=\alpha \cdot q+\left(\frac{z^{c}}{\varphi_{1}}+\frac{z^{p}}{\varphi_{2}}\right)+\sqrt{Z_{1}^{x} \frac{\varphi_{1}}{\varphi_{3}}+Z_{2}^{x} \frac{\varphi_{2}}{\varphi_{3}}+2 Z_{3}^{x}} \cdot \sqrt{z^{n} q+\gamma \varphi_{3} q^{2}}
$$

In case all sections of the network satisfy the conditions of hypothesis 2 , the optimum freight traffic depends on costs for development of production and distribution points.

In case the conditions of hypothesis 3 are satisfied with $q>0$ for some section, then the optimum number of batches, and time for loading, transportation and unloading can be defined by the formulas

$$
\begin{gathered}
n=\sqrt{\frac{q^{2}}{\gamma^{2}}\left(\sqrt{\frac{Z_{1}^{x} z^{c}}{2}+\frac{Z_{2}^{x} z^{n}}{2}}\right)^{2}} \\
t_{1}=\sqrt{q} \cdot \sqrt{\frac{2 z^{c}}{Z_{1}^{x}}} ; \quad t_{2}=\sqrt{q} \cdot \sqrt{\frac{2 z^{p}}{Z_{2}^{x}}} ; \quad t_{3}=n \cdot \sqrt{\frac{z^{n}}{Z_{3}^{x} q}}
\end{gathered}
$$

And the local cost function is brought to the following:

$$
f(q)=\alpha \cdot q+\sqrt{Z_{3}^{x} z^{n} q}+\sqrt[3]{4 \gamma\left(\sqrt{Z_{1}^{x} z^{c}}+\sqrt{Z_{2}^{x} z^{p}}\right) q^{2}}
$$

In today's state of economy, special importance is gained by railway transport that forms tariff component in the products pricing structure. Reduction of this component is provided by optimizing costs for production and technological processes in railways. Agreement of economical and business interests of transportation process organizers and infrastructure facilities owners can be reached due to optimization of cost management based on modeling and forecasting of products supply on a local transport network.

\section{Conclusion}

As a result of the study the model of cost management for technological processes in railways has been developed. It is based on splitting and rationalization of costs for freight 
transportation, supply organization on sections of a transport network, loads storage and cargo-handling operations, maintenance and development of infrastructure. The obtained cost functions enable to determine the optimum number of load batches distribution of which is ensured by agreement of business interests of market players in the economic system of the country and its regions. Further research shall be focused on parametric (digital) modeling of processes in polygon technologies.

\section{References}

1. Strategija razvitija zheleznodorozhnogo transporta v Rossijskoj Federacii do 2030 goda ot 17 ijunja 2008 № 877-p [Strategy for the development of railway transport in the Russian Federation until 2030 of June 17, 2008, No. 877-p]. (in Russian).

2. M. Andersson, M. Berglund, J. Flodén, C. Persson, J. Waidringer, Research in Transportation Economics, 66, 59-69 (2017).

3. G. Zembri-Mary, European Transport Research Review 2017, 9:51 (2017).

4. L. Márquez, V. Cantillo, Journal Transportation Planning and Technology, 36(6), 529546 (2013).

5. K. Kerkman, K. Martens, H. Meurs, Journal of Transport Geography, 60, 155-166 (2017)

6. A.A. Reger, Zheleznodorozhnyj transport [Railway transport], 2, 62-65 (2014). (in Russian)

7. I.B. Repina, Nauchnye problemy transporta Sibiri i Dal'nego Vostoka [Scientific problems of transport in Siberia and the Far East], 1, 114-117 (2013). (in Russian)

8. A.E. Bashirov, D.S. Rubchenko, Zheleznodorozhnyj transport [Railway transport], 8, 46-50 (2017). (in Russian)

9. A.N. Smorodin, Zheleznodorozhnyj transport [Railway transport], 6, 56-59 (2016). (in Russian)

10. J-M.A. Hiltrop, Europ. Management, 14(3), 243-254 (1996).

11. V.A. Bystrov, T.N. Borisova, N.Yu. Grekova, O.G. Tregubova, P.K. Dyakov, Fundamental'nye issledovanija [Basic research], 7-1, 66-71 (2016). (in Russian)

12. V.S. Vorobyev, A.L. Lanis, Yu.V. Popova, News of higher educational institutions. Construction, 7(703), 100-109 (2017). (in Russian)

13. L. Li, R.R. Negenborn, B. De Schutter, Proceedings ITSC 6728399, IEEE Conference on Intelligent Transportation Systems, 1224-1230 (2013). 